\title{
Assessing Text Easibility of University Students' EFL Writing in Tanzania
}

\author{
Erasmus Akiley Msuya \\ Department of Foreign Languages and Linguistics \\ P.O. University of Dar es Salaam, Box 35048 \\ Dar es Salaam, Tanzania \\ Tel: 255-756-537-686_E-mail: Msuyaerasmus@gmail.com \\ Received: March 12, 2017 Accepted: July 11, 2017 Published: July 16, 2017 \\ doi:10.5296/jsel.v5i1.11554 URL: https://doi.org/10.5296/jsel.v5i1.11554
}

\begin{abstract}
This study is a comparative appraisal of text easibility of EFL University student writers across six disciplines: Language and Linguistics, History, Development Studies, Botanical Science, Chemistry and ICT. Each of these was comparably appraised across three years of study that characterize academic length for a Bachelor's Degree in such disciplines. The study participants were 90 in total (30 from each year of study) and were purposively selected by the criteria of their willingness to cooperate. Each was served with a short writing task relevant to their area of study but specifically requiring them to link what they were being talk with their career aspirations. Their essays were word processed, copied and pasted to Coh-Metrix software for text easibility analysis in the aspects of syntactic simplicity, word concreteness, referential cohesion and deep cohesion. The findings revealed that that deep cohesion was high in History, Development Studies, Chemistry and ICT while narrativity was poor in all disciplines except History and ICT. Narrativity was neither dominant nor poor in any disciplines except ICT. As for years of study first year students did better than other years in deep cohesion and referential and deep cohesions but generally poor in word concreteness. Third year were good in referential cohesion but poor in syntactic simplicity while first year were referential cohesion.
\end{abstract}

Keywords: Text Easibility, Coh-Metrix, Writing, Disciplines 


\section{Introduction}

\subsection{The Notion of Text Readability and Easibility}

The term readability is multifaceted in the sense that it can be applied in computer science, military science, communication studies and in linguistics. In our case (linguistics) it refers to what makes text easier to read than others (DuBay, 2004). This is unlike 'legibility', which include typeface and layout. Readability is exclusively concerned with the linguistic aspects of a text. The examples of readability aspects are word count, word concreteness, syntax and cohesive devices.

Readability has been a favourite area for applied linguistics dealing with textual analysis and its implication to language education believing that predicting the difficulty level of a reading text for second language learners is important for teachers, educators, and other parties concerned to make sure the text matches the targeted reader's proficiency. Language level relevant reading materials would promote a reader's language development. In other words, texts that are too easy would bore readers while those that are too difficult could weaken learners' motivation (Carrell, 1987). In venturing towards efficiency in studying readability comprehensively, attest Crossley et al (2007), computational linguists and communication scholars have come up with theories, formulas, and tools which have made it possible to evaluate readability computationally. Among them are Text Ease and Readability Assessor (T.E.R.A), which is a computational tool which was developed to analyse the text in multi-levels as it includes indices that more directly correspond to psycholinguistic and cognitive models of reading (Crossley et al., 2011).

DuBay (2004) affirms that there have been many attempts to predict text difficulty using what he dubbed 'shallow indices' such as vocabulary and sentence length in the 1920s and that in the 1950s progress and research on the formulas were popularized by researchers such as Rudolf Flesh, George Klare, Edgar Dale and Jeanne Chall. These resulted into development of such formulas such as Flesh Reading Ease Formula, Gunning Readability Index, Fog Count, and Fry Grade Level were introduced. However, McCarthy et al. (2006) opine that these traditional readability formulas received a lot of criticism because of their shallow assumption which analyses limited features of texts, citing example of Flesh Reading Ease Formula and Flesh- Kincaid Grade Level Formula which were noted to rely mainly on word length to assess the difficulty of texts. While many comprehension models proposed that there are multidimensional levels of understanding that emerge during the comprehension process, readability formulas assume only a uni-dimensional representation (McNamara et al., 2011).

In a quest for more comprehensive tool for readability analysis, Coh-Metrix Common Core Text Ease Readability Assessor (T.E.R.A) was developed the goals of which include improving our ability to measure text difficulty (Crossley and McNamara, 2010). McNamara et al (2011) observe that the original Coh-Metrix offers more than 52 linguistic indices to the public but Coh-Metrix T.E.R.A has selected only five indices which proved to be useful in analysing lower grade texts as the indices. The five indices are narrativity, syntactic simplicity, word concreteness, referential cohesion and deep cohesion. 
This tool is congruent with theories of discourse and text comprehension that describe comprehension at multiple levels. The six levels of comprehension that are considered in developing Coh-Metrix are words, syntax, the explicit text base, referential situation model, the discourse genre and rhetorical structure, and the pragmatic communication level (McNamara et al., 2014). However, the absence of situational settings, speakers, audience and broader contexts when a text is analysed results in few findings at the sixth level.

Among success stories attribute to this tool is its ability to analyse linguistic features and detect subtle differences in different types of texts in many studies. For example, Crossley (2006) demonstrated that Coh- Metrix can differentiate between authentic and simplified texts as accurately as human participants and this was supported by another study by Crossley, McCarthy \& McNamara (2007). Additionally, Coh-Metrix was found to be able to distinguish between authentic and simplified text essays written by different levels of proficient writers (Crossley et.al., 2010 and Crossley et. al 2011), different text levels-advance, intermediate, beginner (Crossley, et al., 2011) and essays that are written by first language writers and second language writers of English (Crossley and McNamara, 2009). From all these testimonies, one can comfortably affirm that Coh-Metrix is able to analyse various types of texts.

More specifically and relevant to the current study is the fact that Coh-Metrix T.E.R.A $\mathrm{h}$ a s been found to offer the source of difficulty by presenting five easibility indices Easability indices as variables that promote comprehension (McNamara et al, 2014). The variables, which were the ones that were in focus in this study, are narrativity, syntactic simplicity, word concreteness, referential cohesion and deep cohesion. Using this tool, a text can have a high percentage of narrativity and syntactic simplicity but a low percentage of other three variables. The result can be a various score combination of the five variables. It can offer a complete picture of the potential challenges that may be faced by a reader as well as the potential scaffolds in the text (McNamara et al., 2011).

\subsection{Empirical Studies}

A number of studios have been conducted in textual assessment. Quintero et al. (1998) analyzed the measures used in identifying development in L2 writing and noted three categories related to different aspects of writing development: fluency, accuracy, and grammatical and lexical complexity.

Diane-Larsen (2006) studied five Chinese English language learners over a ten month period. They met once a week and over the ten months produced four written narratives about past time events and then later orally presented the stories. The written stories were analysed for fluency, grammatical complexity, and vocabulary complexity. The results showed overall improvement over six months with regard to fluency, accuracy, and complexity of grammar and vocabulary.

As for Verspoor et al. (2008) in their case study of an advanced learner of English enrolled as an English major at the University of Groningen, The Netherlands, they examined sentence complexity using the number of finite verbs divided by the number of words per sentence 
along with the length of the noun phrases, the use of academic vocabulary from Coxhead's Academic Word List, lexical diversity, and sentence length. They found greater variability occurred before the learner made what they referred to as developmental jump.

Baba and Nitta's (2010) study focussed on EFL writing development in Japan using Coh-Metrix with a visual analysis of nonlinear individual development. They studied 46 students' writing on a repeated assignment over the course of one year. They noted that their students improved in lexical diversity and grammatical complexity more than other text characteristics, such as speed and coherence. Their development patterns varied greatly.

McNamara et al. (2010) study involved 120 college students' essays graded by experts. The essays were untimed and written outside of class. They used Coh-Metrix to calculate scores on 53 indices and found that only 3 indices predicted the quality of the essays: syntactic complexity, lexical diversity, and word frequency. They concluded that "...essay quality is judged largely by the sophistication of the writing rather than the ease of processing" (p. 63).

Graesser et al. (2011: 223) analysed 37 texts of paragraph length covering K1 to 12th grade levels and they found that grade levels were primarily correlated with narrativity and syntax with only small variation in referential and causal cohesion across grade levels.

Crossley and McNamara's (2011) study was on characteristics of L2 writing across four different L1 backgrounds: Czech, Finnish, German and Spanish and compared them to L2 writing. They found significant differences in Coh-Metrix indices for hypernymy, polysemy, stem overlap and lexical diversity. Furthermore, L2 writers used more generic reference lexemes with fewer semantic senses and that there was less cohesion. They concluded that L2 writers share some characteristics regardless of their first language due to the amount and type of linguistic knowledge they have.

Lu's (2010) evaluation of a significant number of essays $(3,678)$ essays by Chinese college students sought to identify writing development using a computational too he developed using 14 measures of syntactic complexity. He recommended seven measures to L2 writing researchers as good candidates for developmental indices. These were: complex nominals per clause, complex nominals per T-unit, length of 4 clause, mean length of sentence, mean length of T-unit, and coordinate phrase per clause and per T-unit.

As for Green, Khalifa and Weir (2013) their study sought to identify which Coh-Metrix variables were better predictors of text difficulty. They using Coh-Metrix 2.0 and VocabProfile to run analyses of 116 reading texts used in Cambridge English to determine text characteristics changing by level. Statistical analysis revealed 15 indices on Coh-Metrix, and Academic Wordlist (AWL) and Offlist wordson VocabProfile as differentiating characteristics.

Ho (2016) investigated the effects of having Learning Assistants as a facet of instruction on the level of textual cohesion in the writing of Academic English learners in college introductory writing classes. She used Coh-Metrix tool for analysis of students' writing cohesion, focusing on the Text Easability components, including narrativity, syntactic simplicity, word concreteness, deep cohesion, referential cohesion, verb cohesion, 
connectivity, and temporality. Her sample consisted of 74 final essays from students in four writing sections, two with Learning Assistants and two without. Results suggested that students exposed to Learning Assistants displayed a higher level of textual cohesion in their writings and their essays had more paragraphs with fewer sentences in each paragraph, when compared to those without Learning Assistants. However, both groups had low levels of word concreteness, suggesting that exposure to Learning Assistants did not improve students' concrete vocabulary.

Zhang (2016) carried out a comparative Coh-Metrix analysis of two Vocational Colleges English textbooks, Successful English for Vocational Colleges and Vocational College English aiming at providing insights on vocational college English teaching in China. He noted that with smaller numbers of sentences in simpler structure and full of more familiar content words, the texts were easier to read, while with larger numbers of words, especially complex modifying noun phrases, in greater lexical diversity, the texts were more difficult to read.

In the realm of semantics, Gui's (2010) study sought to make a comparative investigation of lexical meanings and meaning relations in L1 and L2 writings at the deep structure level via Coh-Metrix tool. She found that L2 writings used more known information to establish lexical co-referentiality while L1 writings manifested more lexical variety and sophistication.

Again in the area of lexical semantics, Törnqvist (2015) studied Swedish students' texts in 1999 and 2009 seeking to find cohesive evidence indicating a change of quality influenced by the development of the Internet. The researcher used Coh-Metrix, and the results showed that the student texts from 2009 had higher lexical diversity, suggesting a larger vocabulary, which is closely connected to text quality. The results also showed a higher use of deep cohesion in the texts from 2009, which suggest that the writers knew how to use connectives.

In the aspect of textbook readability, Ismail and Yusof (2016) investigated the readability of ten local English children story books used by Malaysian children on five aspects: narrativity, syntactic simplicity, word concreteness, referential cohesion and deep cohesion, as provided by the computational tool, Coh-Metrix Common Core Text Ease Readability Assessor (T.E.R.A). They found that the majority of the samples had high narrativity, syntactic simplicity, and word concreteness but average referential cohesion and deep cohesion. The results further revealed that there was lack of attention given to the aspect of cohesion in children story books. In the same aspect of text readability, Sarawit (n.d.) analysed the SRA Lab 3B Rose Level students' writing using Coh-Metrix indices at lexical, syntactic and semantic levels. The students were from Nareseum University International College. The study revealed the relationship between connectives and reading ease: The higher incidence of causal and logical connectives related to a higher Flesch ease score. Also, the Flesch grade level correlated with the number of modifiers before the noun phrase for which the number of words before the verb also correlated.

Kasule (2011) assessed ESL primary school readers' self-assessment of their own skills of determining text readability in Botswana, suing an online software tool and a cloze test. The results showed that the majority found the text difficult and only $18 \%$ could read the text 
unassisted. It is concluded that the teachers' awareness of the readability issues is helpful for effective reading instructions during the critical formative years of school.

In her study seeking to establish linguistic differences between fantasy and science fiction, Ida (2015) used computational Coh-Metrix software to analyse 15 different authors, out of whom 5 were writers in both genres. The data were analysed via ANOVA, correlations, t-tests and general scrutinising of data. She found a lot of weak correlations and significant differences but a lack of patterns while comparing text and text groups. Generally, the authors who wrote both fantasy and science fiction seemed to conform more to the fantasy genre than the science fiction except for four measures-descriptive, referential cohesion, LSA and lexical density- where the authors writing in both genres seemed to conform more to science fiction than fantasy.

Going through the survey of literature reviewed, the comparability has been in the aspects effectiveness of assisting in the language learning process, the text difficulty levels and authorship of the reading materials, and in assessing development of acquisition of writing skills across time. Little if not nothing at all has been done to assess text easibility of written essays comparing different disciplines and across years of study, both at one point in time. The current study is a contribution towards such omission.

\section{Respondents, Materials and Instrumentation}

The study made use of Coh-Metrix too to analyse essays by 90 University of Dar es Salaam undergraduate students 30 from each of the three years of study and from the 30 students 5 were from each of the six disciplines that were identified, as summarized in table 1 below:

\begin{tabular}{|c|c|c|c|c|c|c|c|}
\hline $\begin{array}{l}\text { Year of } \\
\text { Study }\end{array}$ & $\begin{array}{l}\text { Language and } \\
\text { Linguistics }\end{array}$ & History & $\begin{array}{l}\text { Development } \\
\text { Studies }\end{array}$ & $\begin{array}{l}\text { Botanical } \\
\text { Science }\end{array}$ & Chemistry & ICT & Total \\
\hline $1^{\text {st }}$ & 5 & 5 & 5 & 5 & 5 & 5 & 30 \\
\hline $2^{\text {nd }}$ & 5 & 5 & 5 & 5 & 5 & 5 & 30 \\
\hline $3^{\text {rd }}$ & 5 & 5 & 5 & 5 & 5 & 5 & 30 \\
\hline Total & 15 & 15 & 15 & 15 & 15 & 15 & 90 \\
\hline
\end{tabular}

The students were asked to volunteer for the exercise and each was given a short writing task relevant to their area of study which specifically instructed them to link what they were being talk with their career aspirations. The essays were word processed and each was pasted into Coh- Metric linguistic analysis tool focussing on five aspects of text easibity, namely: syntactic simplicity, narrativity, word concreteness, referential cohesion, and deep cohesion. According to Graesser et al. (2011: 223), the aspects can be described as follows: The first is narrativity which measures the extent to which the text tells a story and is characterized by a 


\section{Ml Macrothink}

higher percentage of verbs, adverbs, and intentional actions and events than informational passages, it tends to be about familiar topics, and it employs high frequency words and simple syntax. The second factor is syntactic simplicity which is characterized by fewer words and simpler syntactic structures meaning shorter noun phrases. The third factor is word concreteness which means the content words are concrete and can more easily be visualized. The fourth factor is referential cohesion which means overlap in words and ideas in the passage. The final factor used in the computational analysis is causal cohesion which accounts for the use of causal and intentional connectives in the passage.

Having obtained results of each of the essays in percentages, means were computed per year of study combinations of respondents and the disciplines were used the thematic chunks and were therefore treated as subsections of the data presentation.

\section{Findings}

The findings have been presented according to the six disciplines that were involved, which were Language and Linguistics, History, Development Studies, Botanical Science, Chemistry and ICT.

\subsection{Language and Linguistics}

The language and linguistics essays produced the following outputs as summarized in figure 1 below.

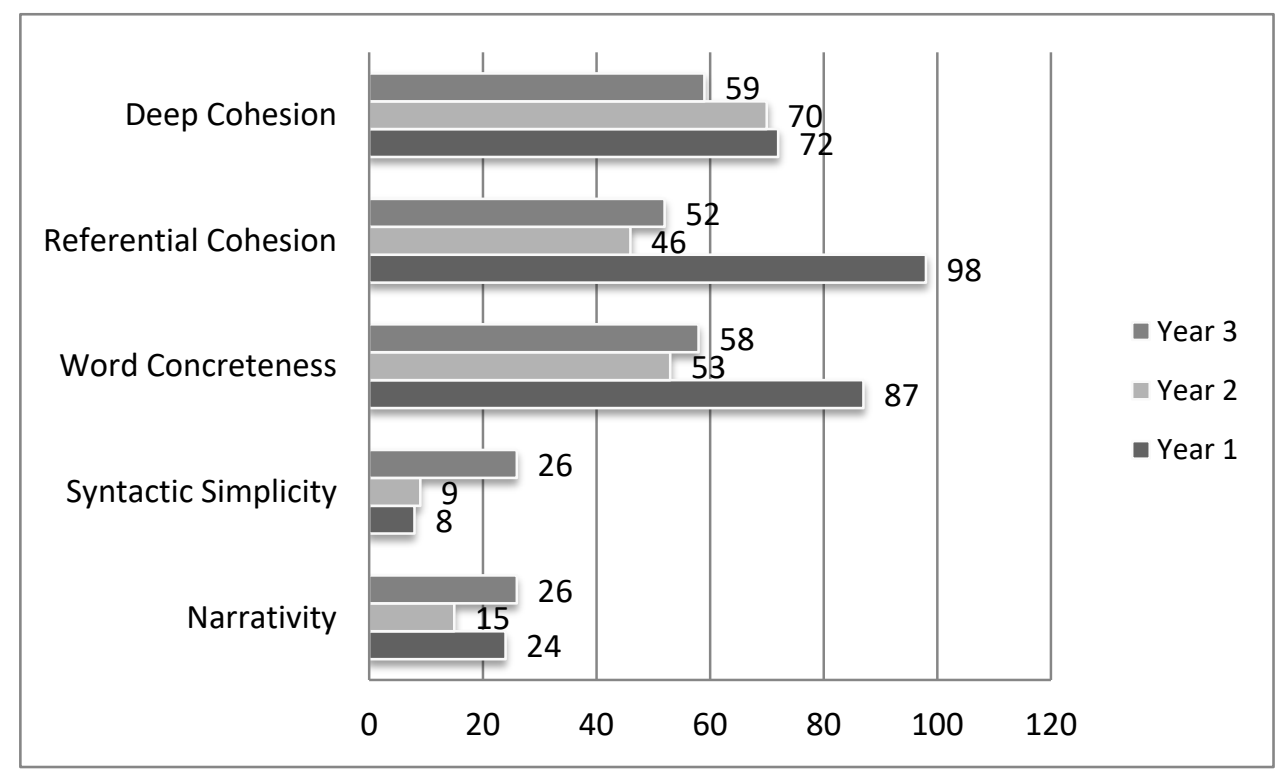

Figure 1. Comparative Text- easebility in the Area of Language and Linguistics

In the area of language and linguistics, referential cohesion was observed more notably in the essays by $1^{\text {st }}$ year students, followed by third year students, while the least in this aspect was second year students. As for word concreteness, first year student respondents also took the lead with a mean score of 57 , followed by $3^{\text {rd }}$ year students (58 mean score) and lastly second 
year (53 mean score). Third rank was deep cohesion where $1^{\text {st }}$ years and $2^{\text {nd }}$ years had a marginal difference of 2 scores by having 72 and 70 mean scores, respectively. Third year were not as good in their essays in this area as their counterparts since their mean score was slightly above half (59). Syntactic simplicity and narrativity featured rather lowly. In these two aspects, third year students had mean scores of 26 each. In the narrativity aspect the first and second year student essays were comparably far better than in the aspect of syntactic simplicity by having mean scores of and 26 and 24 , respectively.

So, in general, language and linguistics essays were good in the easerbility aspects of deep cohesion and concreteness but poor in narrativity and syntactic simplicity.

\subsection{History}

History was another discipline in Humanities that was included in the study. The findings on history students' essays are as presented in figure 2 below.

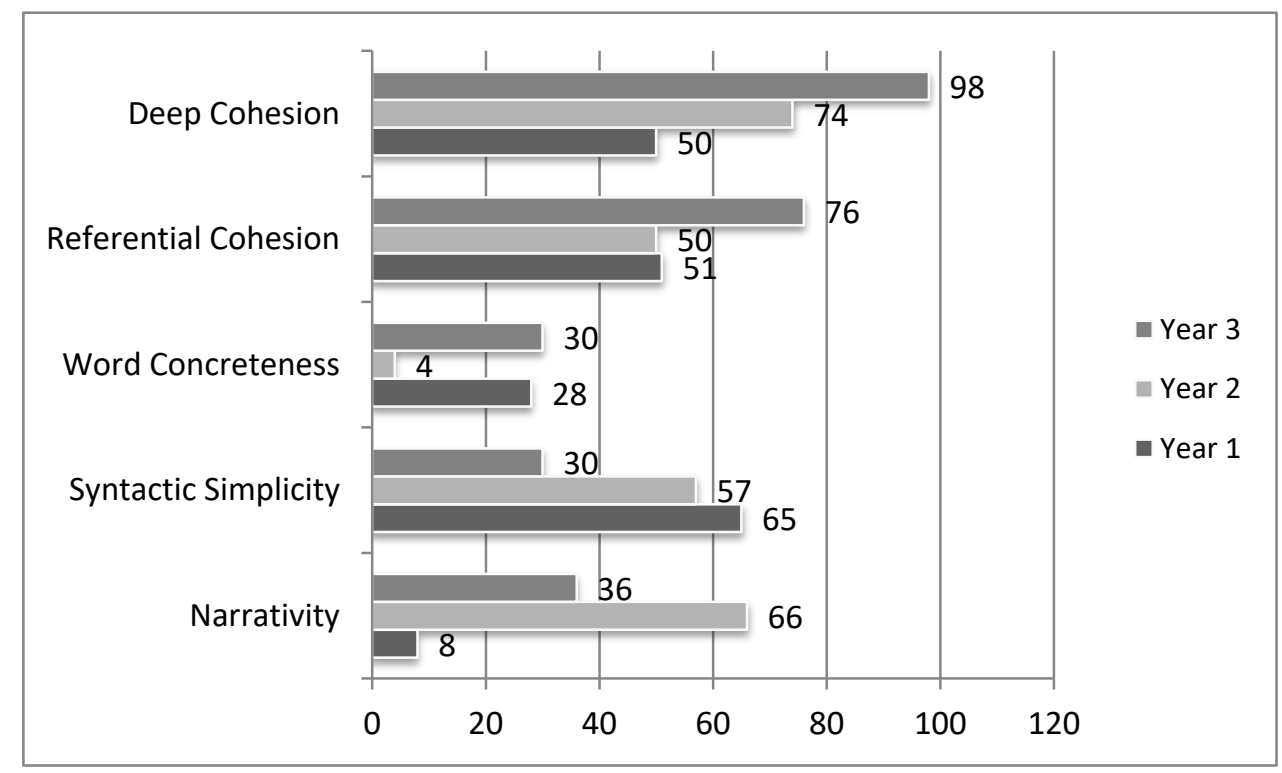

Figure 2. Comparative Text-easebility Across Years of Study of History Essays

In History, essays by third year students had highest mean of 98 in deep cohesion followed by second year with a mean score of 74 while first year's mean score was only a half in the referential cohesion aspect. Referential cohesion was thus comparably the best with mean score of 76 while first and third year essays were 51 and 50, respectively. In these two aspects, the duration of exposure to academic writing have positive contribution to quality of essays in text easerbility. Narrativity was notably high in the essays by second year students but poorest in essays by first year students. Conversely, essays by first year students were better in syntactic simplicity followed by essays by second year students. Third year essays students were the poorest in syntactic simplicity. The aspect that was the poorest for all groups was word concreteness the extreme case being second year essays with mean score of only 4.

Deep cohesion, as viewed by Graesser et al. (2011) has its basis in exploration of the extent 


\section{Ml Macrothink}

to which ideas in the text are connected with casual, intentional or temporal connectives.

\subsection{Development Studies}

This is discipline which, though biased towards Social sciences has aspects inter-disciplinarity in it. In the case of university of Dar es salaam, it is a course with university-wide student membership. However, the respondents for this study were drawn from among those who belong to courses related to humanities the results of which are as summarized in figure 3 below.

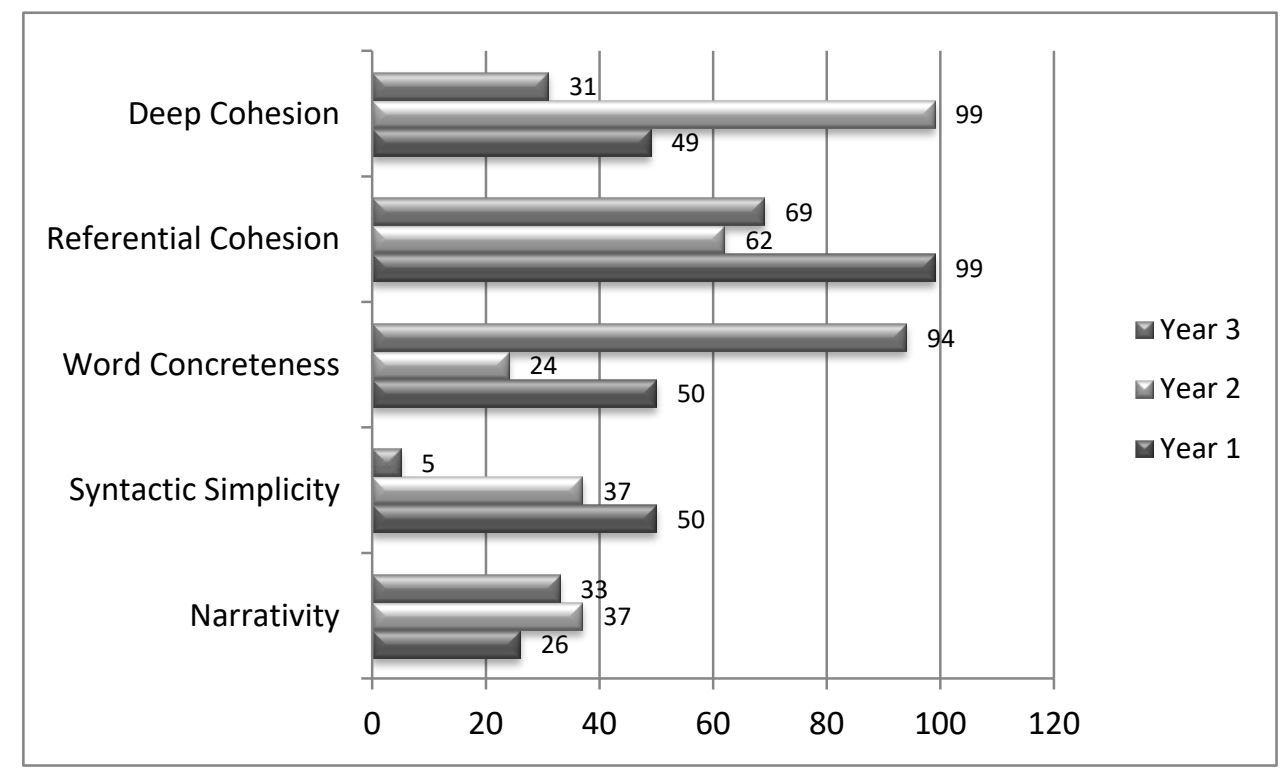

Figure 3. Comparative Text- easerbility in Development Studies

As shows in figure 3 above, essays by development studies dominated in referential cohesion notably in first year group who had up to $99 \%$ while year two and three had above two thirds each (62\% and 69\%, respectively). Second year students essays were equally very high in deep cohesion (99\%) but other years of study did not do very well in this aspect since neither group reached $50 \%$ in deep cohesion.

Syntactic simplicity and narrativity did not feature prominently in all years of studies except for first year (in the aspect syntactic simplicity, which was half (50\%). The rest were $37 \% 37$ and below. Of the extreme here were third year essays the mean score of which was the lowest $(05 \%)$. This means that the essays by third year students were syntactically too complex to fall into 'good books' of good academic writing.

Another observation is that essays by development studies students - irrespective of the year of study they were in were far short of ideals of narrativity characterizing good coherence in academic writing.

\subsection{Botanical Science}

Botanical science is a discipline that falls within natural or 'hard sciences' and its writing has unique features and has conventions called scientific writing. The Chemistry students were 
involved in this study to see whether those conventions may have marked differences with Humanities and Social Sciences and the analytical output of their essays in text easibility is as summarized in figure 4 below.

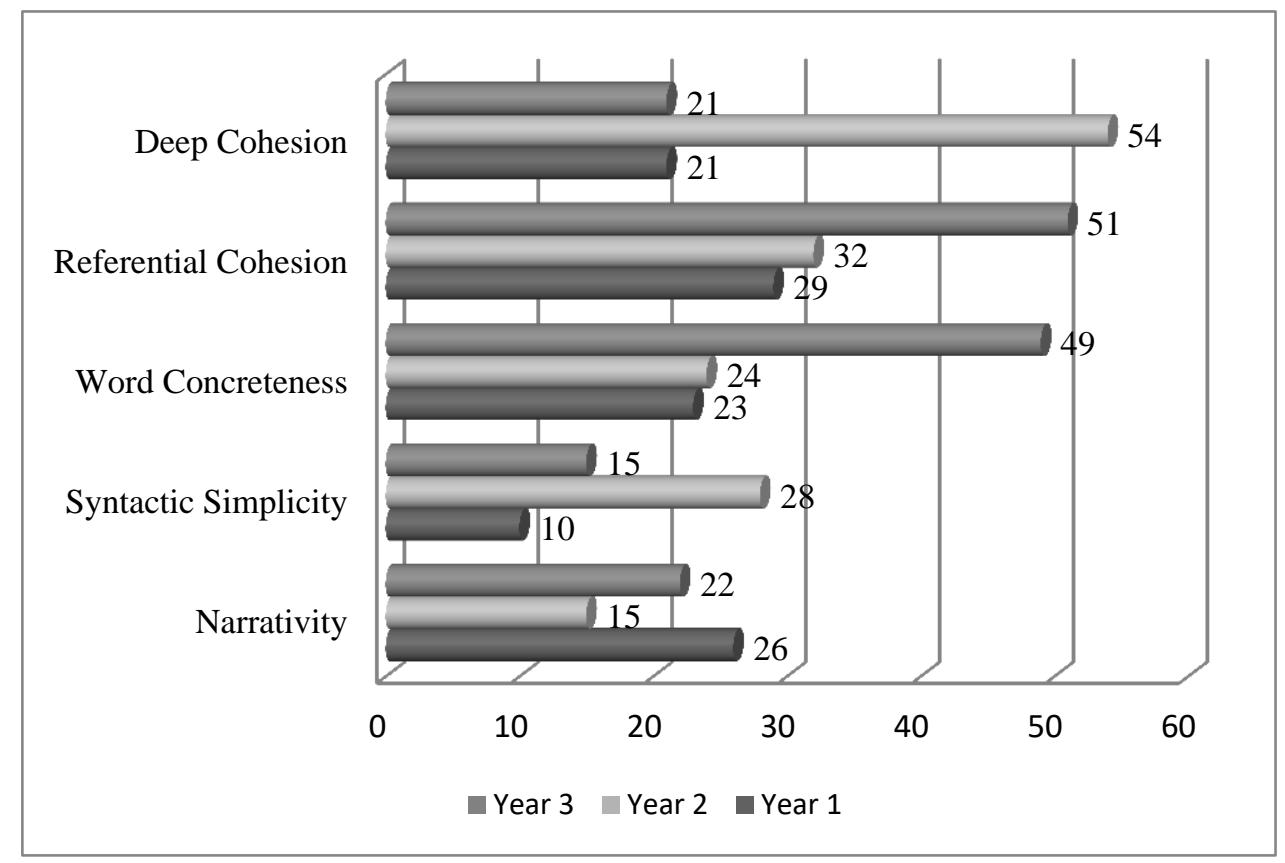

Figure 4. Comparative Text-easibility of Essays by Botanical Science Students

Overall impression one gets from the data in text easibility of the essays by Botanical Science students is that their writing not have any significant peculiarities in any of the aspects since none went beyond 54\%. Deep cohesion was in the essays by second year students was comparably better by being above $50 \%$ even though their colleagues in the first and third years only scored $21 \%$ each. As for referential cohesion third year essays were relatively better with $51 \%$ first and, while the quality of second and third year students was found to be highly wanting in referential cohesion since they had only 295 and 32\%, respectively. Ranking third is word concreteness with third year students taking the lead with $49 \%$ while second and third year essays were half way to third year by both having less than $25 \%$. Word concreteness is a feature highly expected of 'hard sciences' since their description and labels for their references are supposedly highly precise and characterized with heavy borrowing from classical Greek or Latin. Yet these novice EFL science essayists did not make that aspect feature prominently as it should.

The remaining two - syntactic simplicity and narrativity were far less shiny: Their performances ranged between $28 \%$ and $10 \%$.

\subsection{Chemistry}

This is yet another discipline that belongs to hard sciences and its register uniqueness is ideally similar to that of botanical sciences. The resultant data from Coh-Metric analysis and the computation of means are illustrated in figure 5 below. 


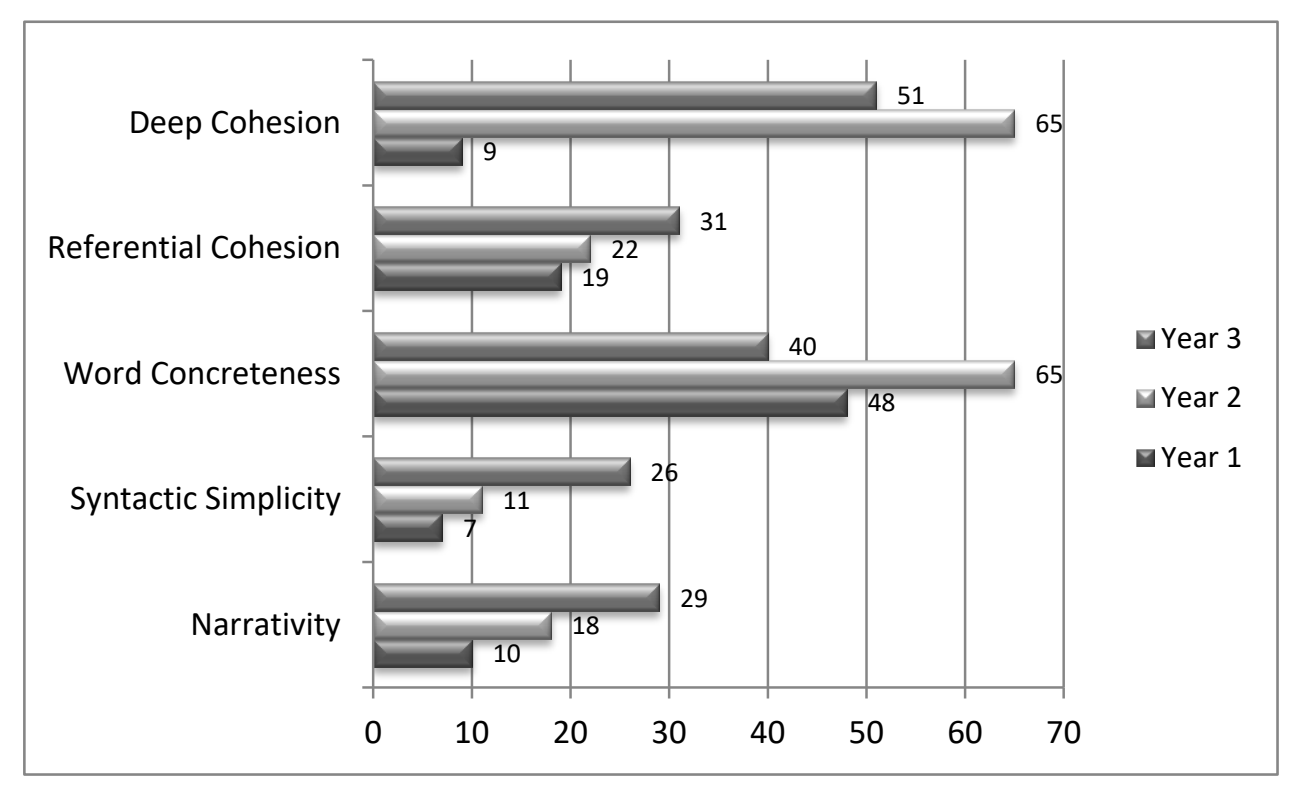

Figure 5. Comparative Text-easerbility of Essays by Chemistry Students

In chemistry the qualities that were observed better than the rest are deep cohesion and word concreteness whereby the highest score for both was $65 \%$ and both by second year students. The lowly performed in these two aspects were essays by first years that had $9 \%$ and $19 \%$ in deep cohesion and word concreteness, respectively.

The rest of the aspects were not well adhered to with referential cohesion with $31 \%$ as the highest score by third year students and $9 \%$ as the lowest by first year students. Syntactic simplicity had third year student $26 \%$ as its highest score and first year's $7 \%$ as its lowest while in narrativity third year's 29\% was the highest and first year's $10 \%$ the lowest. In all three no-so-well-performed aspects, the similar pattern is third year out performing others and first year dragging the fail. This concurs with researches by applied linguists in interlaguage that the longer one is exposed to language (through writing in our context) the more likely their improved language proficiency.

\subsection{ICT}

This was the last discipline whose students, though belong to computer sciences, their knowledge is both applied and interdisciplinary in nature, the response of whose students' essays are summarized in figure 6 below. 


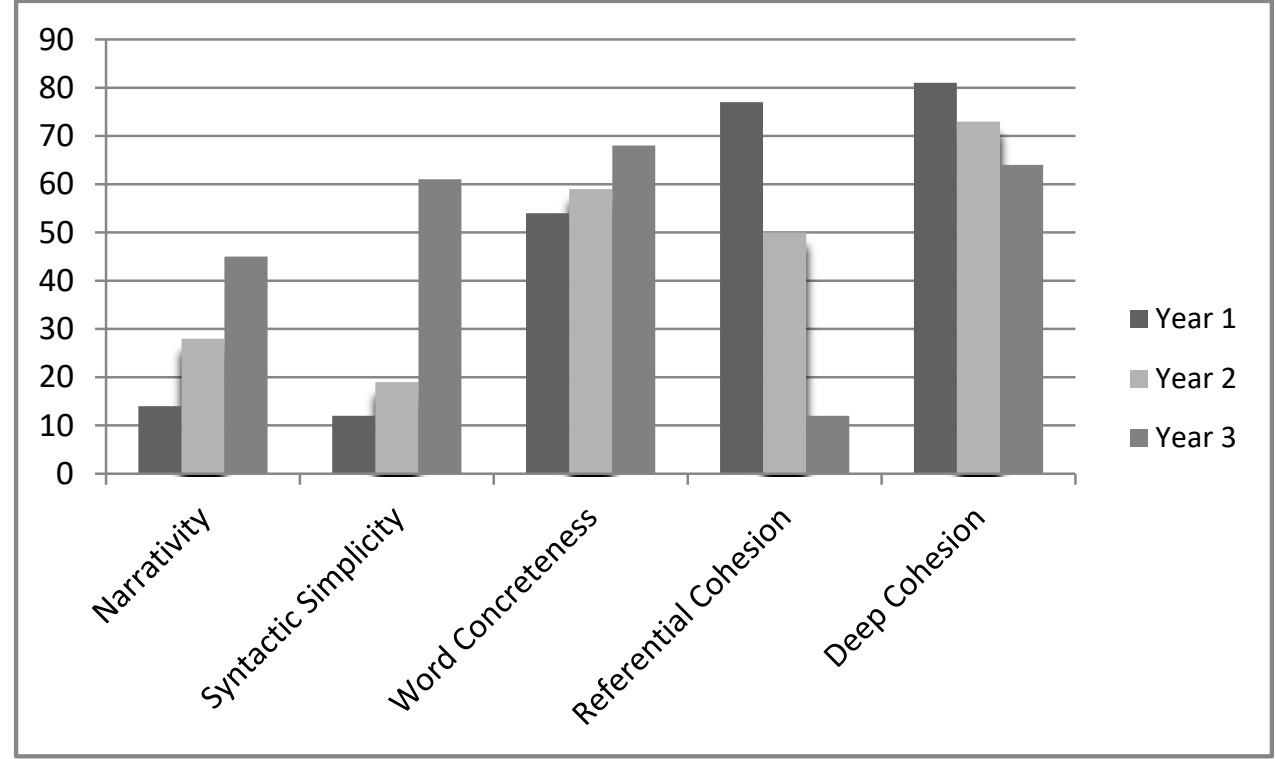

Figure 6.Comparative Text Easibility in Essays by ICT students

In ICT, the qualities of text disciplines had their dominance in referential cohesion and deep cohesion. In both cases, first year's essays excelled over other years of study with $78 \%$ for the former and $80 \%$ for the latter. Second year ranked second for both cases and third year students' essays were comparably the poorest.

Narrativity and syntactic simplicity were qualities in which ICT essays were the poorest with first years doing comparably better than other years of study followed by second year. So there is reverse of performance in the years of study between the highly performed aspects or qualities and the poorly performed ones.

\section{Conclusion}

In general, the findings have revealed that deep cohesion was high in History, Development Studies, Chemistry and ICT, but was low in Botanical Science; and was thus the most dominant of all. Ranking second is Referential cohesion which was high in Language and Linguistics, and in Development Studies. Word concreteness was high only in Chemistry and poor in History. Conversely, narrativity was poor in all disciplines except History and ICT while narrativity was neither dominant nor poor in any disciplines except ICT.

As for years of study first year students did better than other years in deep cohesion and referential and deep cohesions but generally poor in word concreteness. Third year were good in referential cohesion but poor in syntactic simplicity while first year were referential cohesion. None was good in word concreteness and narrativity. 


\section{References}

Baba, K., \& Nitta, R. (2010). Dynamic Effect of Task Type Practice on the Japanese EFL University Student's Writing: Text analysis with Coh-Metrix, Proceeding of the Twenty Third Florida International Research Society Conference (FLAIRS 2010). Retrieved as a PDF file from the Internet, pp. 217-222.

Carrell, P. L. (1987). Readability in ESL. Reading in a Foreign Language, 4(1), 21-40.

Crossley, S. A., \& McNamara, D. S. (2011). Understanding Expert Ratings of Essay Quality: Coh-Metrix Analyses of First and Second Language Writing, International Journal of Continuing Engineering Education and Life Long Learning, 21(3), 171-191.

Crossley, S. A., \& McNamara, D. S. (2009). Computational Assessment of Lexical Differences in L1 and L2 Writing. Journal of Second Language Writing, 18, 119-135.

Crossley, S. A. (2006). A Computational Approach to Assessing Second Language Reading Texts (Doctoral Dissertation, The University of Memphis, United States). Retrieved from http://sunzi.lib.hku.hk/ER/detail/hkul/3851310 on 2nd March, 2017

Crossley, S. A., Louwerse, M. M., McCarthy, P. M., \& Mc Namara, D. S. (2007). A Linguistic Analysis of Simplified and Authentic Texts. The Modern Language Journal, 91(1), 15-30.

Crossley, S. A., \& McNamara, D. S. (2010). Cohesion, Coherence, and Expert Evaluations of Writing Proficiency. In Catrambone, R., \& Ohlsson, S. (Eds.), Proceedings of the 32nd Annual Conference of the Cognitive Science Society, pp. 984-989. Austin, TX: Cognitive Science Society.

DuBay, W. (2004). The Principles of Readability. Retrieved from http://www.impact-information.com/impactinfo/readability02.pdf

Graesser, A., Daniele, C., McNamara, S., \& Kullikowich, J. M. (2011). Coh-Metrix: Providing Multilevel Analyses of Text Characteristics, Educational Researcher, 40(5), 223-234.

Green, A., Khalifia, H., \& Weir, C. (2013). Examining Textual Features of Reading Texts. Cambridge English Language Assessment Research Notes, 52, 24-39.

Gui, L. (2010). A Contrastive Study of Lexical Proficiency between L1 and L2 Compositions via Computerized Assessment. Foreign Language Teaching and Research, 42(6), 445-450.

Ho, P. (2016). Using Coh-Metrix to Analyze Writing Cohesion in Introductory Courses with and without Learning Assistants. Symposium: Fostering Literacy and Learning with Text and Data Mining, Sponsored by UCI Data Science Initiative, UCI School of Education, UCI School of Information and Computer Sciences May 6, 2016.

Ida, W. (2015). Linguistic Differences between Fantasy and Science Fiction: A Coh-Metrx Analysis. Master's English Independent Thesis.

Ismail, A., \& Yusof, N. (2016). Readability of ESL Picture Books in Malaysia. Journal of 
Nusantara Studies, 1(1), 60-70.

Kasule, D. (2011). Textbook Readability and ESL Learners. RASA, 2, 63-76.

Larsen-Freeman, D. (2006). The Emergence of Complexity, Fluency, and Accuracy in the Oral and Written Production of Five Chinese Learners of English. Applied Linguistics, 27(4), 590-619.

Li, H., Cheng, Q., \& Graesser, C. (2015). A Measure of Text Formality as a Human Construct. Proceedings of the Twenty-Eighth International Florida Artificial Intelligence Research Society Conference.

Lu, X. (2010). Automatic Analysis of Syntactic Complexity in Second Language Writing. International Journal of Corpus Linguistics, 15(4), 474-496.

McCarthy, P. M., Guess, R. H., \& McNamara, D. S. (2006). The Components of Paraphrase Evaluations. Behavioral Research Methods, 41, 682-690.

McNamara, D. S., Graesser, A. C., McCarthy, P., \& Cai, Z. (2014). Automated Evaluation of Text and Discourse with Coh-Metrix. Cambridge: Cambridge University Press.

McNamara, D. S. Crossley, S. A., \& McCarthy, P. M. (2010). Linguistic Features of Writing Quality. Written Communication, 27(1), 57-86.

McNamara, D. S., Graesser, A. C., Cai, Z., \& Kulikowich, J. M. (2011). Coh-Metrix Easability Component: Aligning Text Difficulty with Theories of Text Comprehension. AERA 2011. Retrieved from the Internet 23 May 2012.

Quintero, K., Shunji I., \& Hae-Young, K. (1998). Second Language Development in Writing: Measures of Fluency, Accuracy, and Complexity (Technical Report). Manoa, Hawaii: Second Language Teaching.

Sarawit, M. (n.d.). Analysis of Reading Materials using Coh-Metrix along with Students' Reading Comprehension Scores. An Unpublished Seminar Paper, Naresuan University.

Törnqvist, J. (2015). Using Coh-Metrix to Investigate Changes in Student Texts Comparing Student Writing from 1999 and 2009. Unpublished Bachelor's Degree in English Linguistics, Stockholm University.

\section{Copyright Disclaimer}

Copyright for this article is retained by the author(s), with first publication rights granted to the journal.

This is an open-access article distributed under the terms and conditions of the Creative Commons Attribution license (http://creativecommons.org/licenses/by/3.0/). 